\title{
Humidity Sensitive Characteristics of Porous Li-Mg-Ti-O-F Ceramic Materials
}

\author{
Ahmad Kassas $^{1}$, Jérôme Bernard ${ }^{2}$, Céline Lelièvre ${ }^{2}$, David Houivet ${ }^{2}$, Hassan Lakiss ${ }^{3}$, Tayssir Hamieh $^{1 *}$ \\ ${ }^{1}$ Laboratory of Materials, Catalysis, Environment and Analytical Methods (MCEMA/CHAMSI), Doctoral School \\ of Sciences and Technology (EDST), Faculty of Agricultural Engineering and Veterinary Medicine and Faculty \\ of Sciences, Lebanese University, Beirut, Lebanon \\ ${ }^{2}$ LUSAC (EA4253), Site Universitaire, Cherbourg-Octeville, France \\ ${ }^{3}$ Faculty of Engineering, Lebanese University, Beirut, Lebanon \\ Email: ${ }^{*}$ tayssir.hamieh@ul.edu.lb, a.kassas.mcema@ul.edu.lb
}

Received November 27, 2012; revised December 28, 2012; accepted January 5, 2013

\begin{abstract}
Ceramic porous $\mathrm{MgTiO}_{3}$ materials have been prepared by classical solid-state route. The sintered pellets of $\mathrm{MgTiO}_{3}$ with different $\mathrm{LiF}$ contents were characterized for humidity-sensing application. The sintered disks of these mixtures were subjected to capacitance measurements at $20^{\circ} \mathrm{C}$ as function of the relative humidity from which revealed that the Mixture $\mathrm{MgTiO}_{3}+2 \% \mathrm{LiF}(\mathrm{w} / \mathrm{w}$ ) has the better characteristics. The disks were subjected to DC resistance measurements as a function of relative humidity in the range $15 \%-95 \% \mathrm{RH}$. The selectivity of this material was discussed and compared to commercial sensor results. The response and recovery characteristics were assessed.
\end{abstract}

Keywords: Ceramic Humidity Sensor; Magnesium Titanate; $\mathrm{Li}_{2} \mathrm{MgTiO}_{4}$; Capacitance; Resistance

\section{Introduction}

The use of sensors is well established in process Industries, agriculture, medicine, and many other areas, the development of new sensing materials with high sensing capabilities is proceeding with high rate. Consequently, several materials have recently been developed for making the sensitive part of humidity sensors, such as polymeric materials, electrolytic materials and ceramic materials [1].

However, many kinds of ceramic materials such as $\mathrm{MgCr}_{2} \mathrm{O}_{4}-\mathrm{TiO}_{2}$ [2], $\mathrm{ZnCr}_{2} \mathrm{O}_{4}-\mathrm{ZnO}$ [3], $\mathrm{La}_{2} \mathrm{O}_{3}-\mathrm{TiO}_{2}$ [4]..., have been investigated for this application because they are sintered form improve physical, chemical and thermal stable properties [5].

The adsorption of water vapor enhances the surface electrical conductivity (impedance, capacitance, resistance) of ceramic metal oxides [6]. However, the humidity sensors normally exposed not only to water vapor, but to atmospheres containing various other components tend to lose their inherent humidity-sensitive properties during use due to several complicated physical and chemical processes between these components and various materials.

The problems of irreversible response due to chemisorbed water and deterioration due to adhesion of dust, dirt, oil, etc. remain unsolved, and make a new way of

\footnotetext{
"Corresponding author.
}

competition in material developing research. Whatever, the most promising approach seems to be to find a ceramic material with surface resistivity reversibly responsive to relative humidity (RH), which is not easily changed by repeated water vapor adsorption-desorption cycles and repeated heat-cleaning cycles at high temperatures, and selective to water vapor molecules.

Magnesium titanate $\mathrm{MgTiO}_{3}$ ilmenite structure, is known as a compound for type I ceramic capacitors $[7,8]$, and which have important applications in microwave communication systems [9]. Nevertheless, sintered ceramic disks $\mathrm{MgTiO}_{3}$ with $\mathrm{LiF}$ additive have shown recently sensitivity to humidity [10]. A study of the sensitivity of $\mathrm{MgTiO}_{3}-\mathrm{LiF}$ porous ceramic materials is carried out in this paper.

\section{Experimental Part}

\subsection{Experimental Procedure}

$\mathrm{MgTiO}_{3}$ powder with stoechiometry $\mathrm{Mg} / \mathrm{Ti}=1.025$ was synthesized by the classical solid-state route [11]. The starting powders ( $\mathrm{MgO}$ Cerac $99 \%, \mathrm{TiO}_{2}$ Prolabo 99\%) were mixed together for one hour in demineralised water by attrition milling (Dyno Mill KDLA, BACHOFEN, Switzerland) using $0.8 \mathrm{~mm}$ diameter yttried stabilized zircon balls (YTZ grinding media TOSOH).

The powder mixture was then calcined in air at $1000^{\circ} \mathrm{C}$ for one hour in order to form the ilmenite phase. The 
phase formation was noticed by X-ray diffraction. The diffraction patterns were collected using a SIEMENS D 5005 diffractometer with $\mathrm{CuK \alpha}(\lambda=1.5405 \AA)$, in the range $\left.15^{\circ}-85^{\circ}(2 \theta)\right)$.

After calcinations, LiF was added and the powders were milled in a planetary agitator (Pulverisette FRITCH with agate bawl and balls). Three compositions are prepared by mixing $1 \%, 2 \%$ and $5 \% \mathrm{LiF}(\mathrm{w} / \mathrm{w})$ with the prepared $\mathrm{MgTiO}_{3}$ (respectively called ML1, ML2 and ML5). The $1 \%$ by mass of lithium fluoride compound corresponds to $4.97 \%$ (as molar percentage).

The different compositions were pressed at 2000 $\mathrm{kg} \cdot \mathrm{cm}^{-2}$ (at a pressure of $74 \mathrm{MPa}$ ) to obtain disks $25 \mathrm{~mm}$ in diameter and around $2 \mathrm{~mm}$ thick. Densification behavior was studied by dilatometric measurements performed in air on TMA92 SETARAM dilatometer, with $300^{\circ} \mathrm{C} \cdot \mathrm{h}^{-1}$ heating and $1200^{\circ} \mathrm{C} \cdot \mathrm{h}^{-1}$ cooling rates. The disks were fired in air at different temperatures, with $150^{\circ} \mathrm{C} \cdot \mathrm{h}^{-1}$ heating and cooling rates and one hour dwell time. Interconnected porosity was measured using MICROMERITICS AutoPore III mercury porosimeters.

\subsection{Electrical and Dielectrical Measuring Instruments}

After sintering, a design was screen printed (gold ink) on the surface of the samples in order to obtain the outline for the electrical and dielectrical measurements. The length of the electrodes is $16 \mathrm{~mm}$ for $1 \mathrm{~mm}$ width, with $0.5 \mathrm{~mm}$ space between two electrodes.

After screen-printing, the samples were calcined at $850^{\circ} \mathrm{C}$ in air for 15 minutes with heating and cooling rates of $400^{\circ} \mathrm{C} \cdot \mathrm{h}^{-1}$. The dielectric and electrical properties of surfaces were characterized by measuring the dependence of capacitance and insulation resistance with the moisture rate in air.

An oven "hot-cold" controlled humidity in a range of $10 \%$ to $95 \% \mathrm{RH}$ and a temperature controller between $-50^{\circ} \mathrm{C}$ to $100^{\circ} \mathrm{C}$ was used (SECASI technologies SLH $100)$.

The components were characterized by measurements at various frequencies of their capacitance and their insulation resistance as well as by measuring the insulation resistance under continuous electric field.

To perform measurements under ac field, a multiplexer "Agilent Data Acquisition/Switch Unit 34970A" is used. The RLC bridge "AUTOMATIC PROGRAMMABLE FLUKE PM6306 RCL Meter", shows the change in capacitance and resistance with a (ac/dc) current regulator whose frequency can be change between $60 \mathrm{~Hz}$ and $1 \mathrm{MHz}$.

The electrical properties measurement of the sample by the RLC bridge is based on the method of current and voltage. This method consists in measuring the voltage and current and converted them to binary values, used by the CPU to calculate the electric parameters of the sample. In the case of measurements with alternating voltage a cycle of seven individual measures are stored and evaluated by calculation. Using these values, the microprocessor calculates the first equivalent series resistance $\mathrm{Rs}$, the series equivalent reactance $\mathrm{Xs}$ and the quality factor $\mathrm{Q}(\mathrm{Q}= \pm \mathrm{Xs} / \mathrm{Rs})$ of the sample. The $\mathrm{Q}$ value and the polarity of Xs determine the choice of dominant component of the sample, inductive or capacitive respectively if $\mathrm{Xs}$ is positive or negative. In our case under ac field, $\mathrm{Xs}<0$ and the component is capacitive $\mathrm{C}_{\mathrm{p}}=1 / \omega(1$ $\left.+1 / \mathrm{Q}^{2}\right)( \pm \mathrm{Xs}), \omega=2 \pi \mathrm{N}, \mathrm{N}$ is the frequency.

The resistance of the samples was measured under $\mathrm{dc}$ electric field with a Megohmeter "Sefelec M1500P" by applying a voltage gradient of $70 \mathrm{~V} \cdot \mathrm{mm}^{-1}$ between the electrodes, for 10 minutes before each measurement allowing values to be stable.

The response time of a humidity sensor is the necessary time to give repeatable readings of RH in the atmosphere. The response times of existing sensors on the market range from a few minutes (sensors ceramics and polymers) to three hours (condensation hygrometers).

A device was developed by our team with the aim to measure the response time under ac field. They have two rooms, each with humidity and temperature sensors. In one room, a dry atmosphere of about $4 \% \pm 2.5 \% \mathrm{RH}$ is prepared and in the second room saturated environment of about $95 \% \pm 2.5 \%$ is created. A cap equipped with a sample holder with wire connection to the bridge RLC controlled using a computer to measure the continuous capacitance values of the sample. Rotating cap allows the sample to pass from one room to another (wet to dry and vice versa too) while measuring directly the change in capacitance as a function of time.

\section{Results and Discussions}

When submitting a dielectric material to an electromagnetic field of very low frequency, atomic and ionic polarization mechanisms are activated, and dielectric constant can be significant. However, when the frequency is very high, only the electronic polarization mechanism is active, the others being characterized by inertia of motion of electric charges such that they are not more efficient. Beyond $10^{17} \mathrm{~Hz}$, the mass of electrons is itself too large for they can follow the excitement: the material has a dielectric behavior similar to empty space [12].

At $50 \%$ and $80 \% \mathrm{RH}$, the capacitance change was measured by scanning the measurement frequency between $60 \mathrm{~Hz}$ and $1 \mathrm{MHz}$. Figure 1 presents the results measured for ML2 pellet sintered on a bed of powder for one hour at $1000^{\circ} \mathrm{C}$ with a ramp $150^{\circ} \mathrm{C} \cdot \mathrm{h}^{-1}$. According to the curves, we can notice the importance of the effect of the measurement frequency increases with the percentage of moisture. As frequency increases more, the capacity 


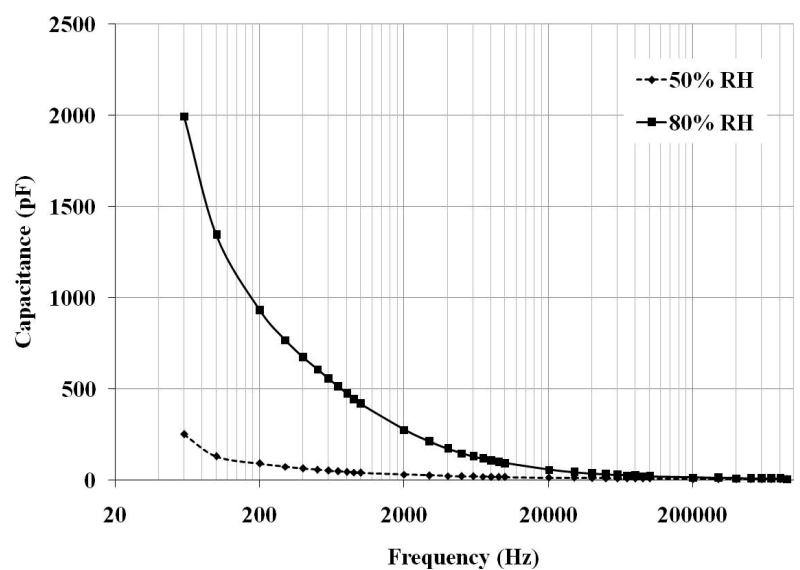

Figure 1. Variation in the capacitance of the ML2 pellet sintered at $1000^{\circ} \mathrm{C}$ as a function of frequency measurement at $50 \%$ and $80 \%$ of relative humidity.

tends to low values. It is therefore advantageous to use a low frequency. Previous studies had determined that the optimal frequency was $100 \mathrm{~Hz}$ [13].

The relative change in capacitance as a function of the $\% \mathrm{RH}$ on the surface of various sintered pellets for one hour at $1000^{\circ} \mathrm{C}$ with a ramp $150^{\circ} \mathrm{C} \cdot \mathrm{h}^{-1}$ is shown on Figure 2.

Whatever the composition of the pellet, the sensitivity is in the same range, between $60 \%$ and $90 \% \mathrm{RH}$ and there is no significant change of the capacitance was detected below $60 \% \mathrm{RH}$. The curves show that the ML1 is the most sensitive pellet and the lowest sensitivity is recorded for ML5 pellet.

According to the structural analysis of surfaces of the pellets sintered at $1000^{\circ} \mathrm{C}$ shown in Figure 3, the pellets ML1 and ML2 have the same phases on the surface: the $\mathrm{MgTiO}_{3}$ and the face-centered cubic (FCC) phase isomorphous with $\mathrm{Mg}_{2} \mathrm{TiO}_{4}$, while the dominant phase in the surface of the pellet ML5 is the FCC phase $\mathrm{Li}_{2} \mathrm{MgTiO}_{4}$.

SEM analysis is made on the surface of transverse sections pellets. It can be seen on the SEM micrographs of pellets sections ML2 sintered for one hour at $900^{\circ} \mathrm{C}$, $1000^{\circ} \mathrm{C}$ and $1100^{\circ} \mathrm{C}$ (Figures 4 (a)-(c)), a change in the micro-structure at the upper surface. Precisely a surface layer with high porosity and rectangular grain form and grain size smaller than $10 \mu \mathrm{m}$ are occurred at $900^{\circ} \mathrm{C}$. The grain size of ceramics at the pellet center does not exceed $5 \mu \mathrm{m}$. At higher sintering temperatures $\left(1000^{\circ} \mathrm{C}\right.$ and 1100 ${ }^{\circ} \mathrm{C}$ ), on pellet surface, the grains size respectively less than or equal to $15 \mu \mathrm{m}$ and $10 \mu \mathrm{m}$ are clearly highlighted. However, the samples sintering with high LiF content (5\% w/w) causes on the surface (Figures 4 (d)-(f)), the formation of oriented grains layer (columnar structure). The grains sizes at the surface of ML5 pellets have vary between 20 and $50 \mu \mathrm{m}$ when the sintering is carried out at $1000^{\circ} \mathrm{C}$ and up to $60 \mu \mathrm{m}$ at $1100^{\circ} \mathrm{C}$. Distinct morphologies types are present on the cross sections for each sintering temperatures. The structural, microstructural and the com-

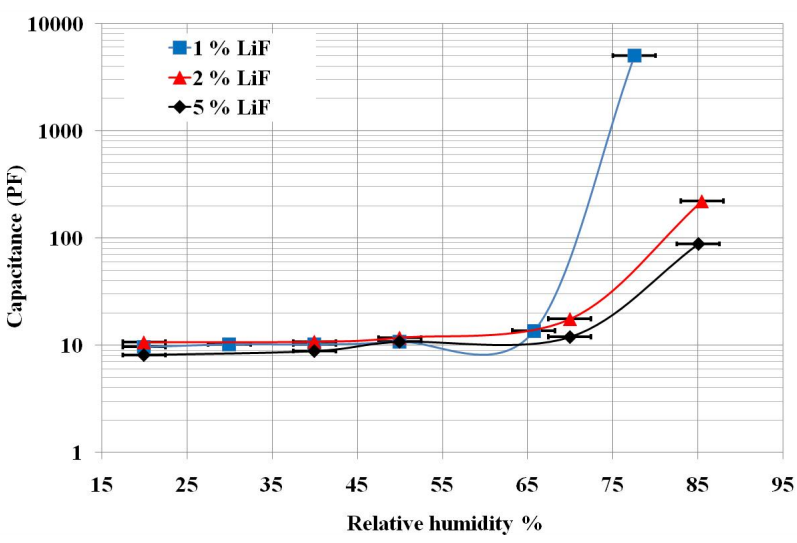

Figure 2. Capacitance variation as a function of relative humidity percentage for pellets prepared with different amount of $\mathrm{LiF}$ sintered at $1000^{\circ} \mathrm{C}$.

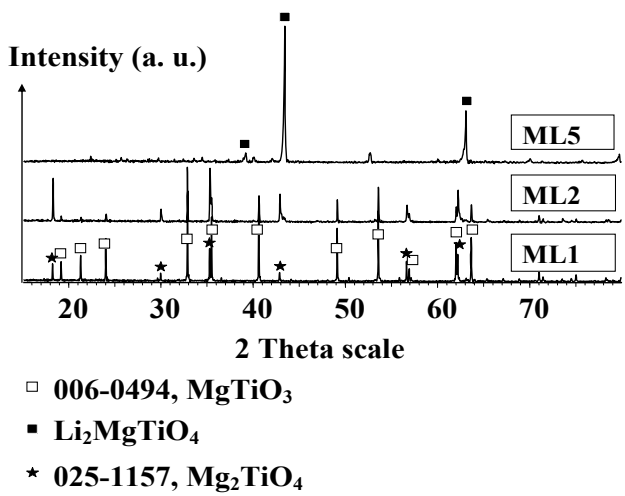

Figure 3. XRD diffractograms of the surfaces of pellets ML1, ML2 and ML5 sintered at $1000^{\circ} \mathrm{C}$.

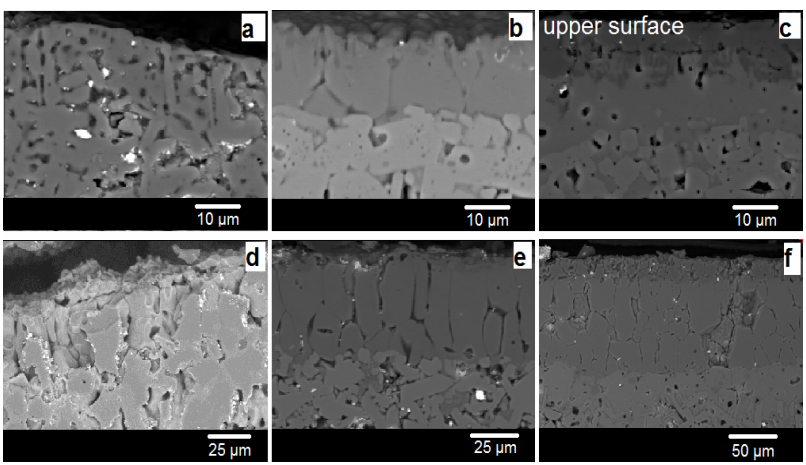

Figure 4. Scanning electron micrographs of ML2 surfaces cross-section (a), (b) and (c) sintered respectively at $900^{\circ} \mathrm{C}$, $1000^{\circ} \mathrm{C}, 1100^{\circ} \mathrm{C}$. And the scanning electron micrographs of ML5 surfaces cross-section (d), (e) and (f) sintered respectively at $900^{\circ} \mathrm{C}, 1000^{\circ} \mathrm{C}, 1100^{\circ} \mathrm{C}$.

positions variation study of those samples as function of sintering temperature, were developed in details in a previous study [14].

On other hand, The volume percentage of total porosity is $19 \% \pm 2 \%$ against $10 \% \pm 2 \%$ respectively for ML1 and ML2 and 15\% $\pm 2 \%$ for ML5 (Table 1) and the distribution 
of pore size shows that the pellet ML1 has a volume percentage of pores with diameters between 0.1 and $3 \mu \mathrm{m}$ $(16 \% \pm 2 \%)$ greater than that of ML2 pellet $(5 \% \pm 2 \%)$ and than that of ML5 $(9 \% \pm 2 \%)$. It can be assumed that the surface sensitivity is greater when the phase surface is isomorphic to $\mathrm{Mg}_{2} \mathrm{TiO}_{4}$ and when the volume percentage of medium pore $(0.1$ to $3 \mu \mathrm{m})$ is important. Given these results, we chose the composition ML2 to study the variation of dielectric and electrical properties, because of its sintering temperature $\left(\mathrm{Ts}=1050^{\circ} \mathrm{C}\right)$ lower than ML1 $\left(\mathrm{Ts}>1350^{\circ} \mathrm{C}\right)[14]$ and its higher sensitivity compared to that of ML5.

The curves of the relative change in capacitance as a function of the $\% \mathrm{RH}$, for the pellets ML2 sintered in a powder bed for one hour at $800^{\circ} \mathrm{C}, 900^{\circ} \mathrm{C}, 1000^{\circ} \mathrm{C}$ and $1100^{\circ} \mathrm{C}$ with a ramp of $150^{\circ} \mathrm{C} \cdot \mathrm{h}^{-1}$ (Figure 5) show that the pellet sintered at $900^{\circ} \mathrm{C}$ is the most sensitive. However, there is no variation detected of capacitance below $60 \%$ $\mathrm{RH}$.

According to the structural study by X-ray diffraction on the surfaces of these pellets (Figure 6), the phases on surfaces of the pellets sintered at $800^{\circ} \mathrm{C}$ and $900^{\circ} \mathrm{C}$ are $\mathrm{MgTiO}_{3}$ and FCC phase $\mathrm{Li}_{2} \mathrm{MgTiO}_{4}$, while the phases on the surfaces of sintered pellets at 1000 and $1100^{\circ} \mathrm{C}$ are $\mathrm{MgTiO}_{3}$ phase and $\mathrm{FCC}$ phase identified as that of

Table 1. Pore volume percentage $( \pm 2 \%)$ distribution as function of pore size distribution and total pore volume percentages (uncertainty: $\pm 2 \%$ ) for the pellets $\operatorname{MLX}($ or $X=1,2$ and 5) sintered at $1000^{\circ} \mathrm{C}$.

\begin{tabular}{ccccc}
\hline $\mathbf{X}$ & $>\mathbf{3} \boldsymbol{\mu \mathbf { m }}$ & $\mathbf{3 - 0 . 1} \boldsymbol{\mu m}$ & $<\mathbf{0 . 1} \boldsymbol{\mu m}$ & \% Total Porosity \\
\hline 1 & 2 & 16 & 1 & 19 \\
2 & 3 & 5 & 2 & 10 \\
5 & 3 & 9 & 3 & 15 \\
\hline
\end{tabular}

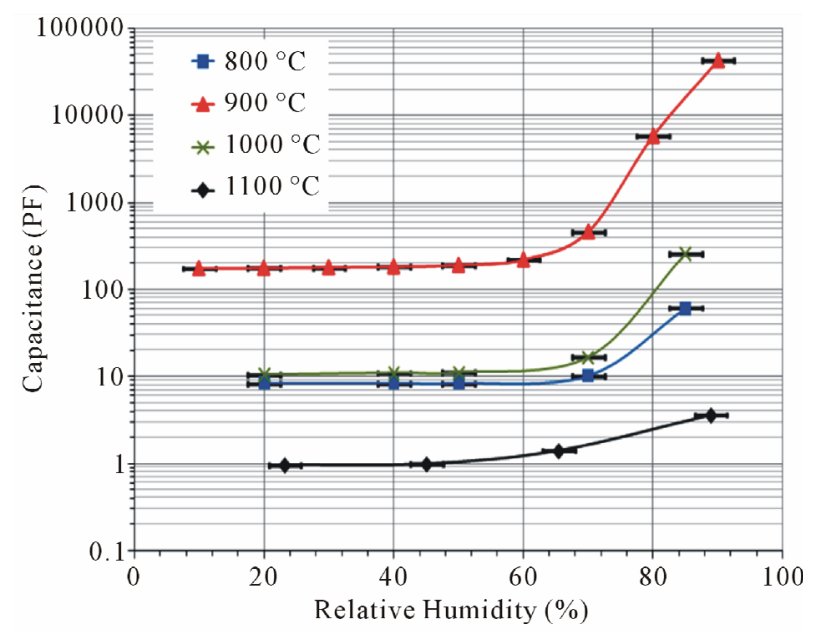

Figure 5. Capacitance variation of the surface of $\mathrm{ML2}$ pellets sintered at $800^{\circ} \mathrm{C}, 900^{\circ} \mathrm{C}, 1000^{\circ} \mathrm{C}$ and $1100^{\circ} \mathrm{C}$ as a function of the relative humidity.
$\mathrm{Mg}_{2} \mathrm{TiO}_{4}$.

The capacitance values of the ML2 sintered at $1100^{\circ} \mathrm{C}$ are lower than capacitance values of the others pellets. However, the same phases are detected by XRD and the porosity values are very close. while, this phenomenon can be explained by the increasing of thick crust formed on the surface of ML2 sample when the sintering temperature increase [14] and this crust layer could distort the measurement of the porosity at $1000^{\circ} \mathrm{C}$ and $1100^{\circ} \mathrm{C}($ Figure 4 (d)).

If we compare the distribution of the volume percentage of pores, according to pore size (Table 2), with the nature of the present phases, we see a correlation between the increasing of volume percentage of pores with small diameters less than $0.1 \mu \mathrm{m}$, and the presence of the FCC phase $\mathrm{Li}_{2} \mathrm{MgTiO}_{4}$ on surface.

Their presence leads to the increased sensitivity of the pellet. Indeed, the pellet sintered at $900^{\circ} \mathrm{C}$ has the largest volume percentage of pores with small diameters $(<0.1$ $\mu \mathrm{m}$ ) of around $14 \% \pm 2 \%$, the others volume percentage of the average pore diameters $(0.1-3 \mu \mathrm{m})$ and (greater than $3 \mu \mathrm{m}$ ) are close to that of the pellets sintered at (1000 and

Table 2. Pore volume percentage $( \pm 2 \%)$ distribution as a function of pore size and total pore volume percentages (uncertainty: $\pm 2 \%$ ) for the pellets $\mathrm{ML} 2$ sintered at $800^{\circ} \mathrm{C}$, $900^{\circ} \mathrm{C}, 1000^{\circ} \mathrm{C}$ and $1100^{\circ} \mathrm{C}$.

\begin{tabular}{ccccc}
\hline $\begin{array}{c}\text { Temperature } \\
\left({ }^{\circ} \mathbf{C}\right)\end{array}$ & $>\mathbf{3} \boldsymbol{\mu \mathbf { m }}$ & $\mathbf{3}-\mathbf{0 . 1} \boldsymbol{\mu \mathbf { m }}$ & $<\mathbf{0 . 1} \boldsymbol{\mu \mathbf { m }}$ & \% Total Porosity \\
\hline $\mathbf{8 0 0}$ & 1 & 0 & 7 & 8 \\
$\mathbf{9 0 0}$ & 1 & 3 & 14 & 18 \\
$\mathbf{1 0 0 0}$ & 3 & 5 & 2 & 10 \\
$\mathbf{1 1 0 0}$ & 2 & 5 & 4 & 11 \\
\hline
\end{tabular}

Intensity (a. u.)

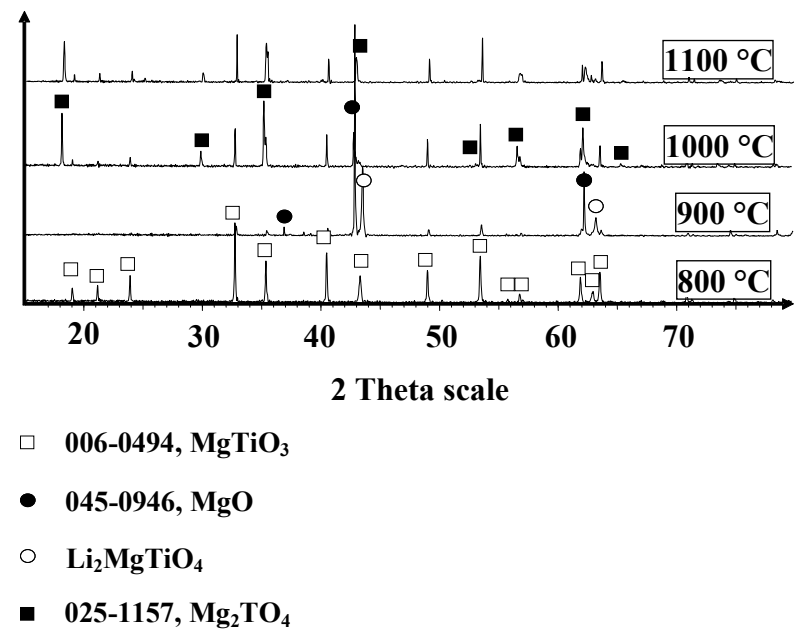

Figure 6. XRD diffractograms of the surfaces of pellets ML2 sintered at $800^{\circ} \mathrm{C}, 900^{\circ} \mathrm{C}, 1000^{\circ} \mathrm{C}$ and $1100^{\circ} \mathrm{C}$. 
$\left.1100^{\circ} \mathrm{C}\right)$.

Measuring the variation of the capacitance surface presented marginally sensitivity between $60 \%$ and $90 \%$ RH and no sensitivity below $60 \%$ RH. It is interesting to found another dielectrical or electrical property, which allows increasing the margin of sensitivity to moisture and preferably ranging over the entire range of $\mathrm{RH}$ as possible between $20 \%$ and $90 \%$.

The relative change in resistance measured with the insulation tester in a wide range of RH for the pellet ML2 sintered at $900^{\circ} \mathrm{C}$. The values range between $200 \mathrm{M} \Omega$ at $20 \% \mathrm{RH}$ and $200 \mathrm{~K} \Omega$ at $90 \% \mathrm{RH}$ (Figure 7). The resistance measurement has a sensitivity of ceramics over the entire range from $20 \%$ to $90 \% \mathrm{RH}$, contrary to what was observed for the capacitive measurement that showed sensitivity between $60 \%$ and $90 \% \mathrm{RH}$.

This variation can be explained by the phenomenon of conduction in low relative humidity atmosphere, provided by the jump of a proton $\left(\mathrm{H}^{+}\right)$of a hydroxyl group to another adjacent group in the chemisorbed layer of water molecules [6]. The activation energy of the proton is very high that is why in a low RH, where a layer of chemisorbed water molecule is present, the resistance values are very high.

At high RH, physisorbed layers of water molecules are formed and the conduction in this case will be handled by the transfer of hydronium ions $\left(\mathrm{H}_{3} \mathrm{O}^{+}\right)$with activation energy lower than that of the $\mathrm{H}^{+}$ion of hydroxyl groups. This leads to lower resistance values.

However, the study of the response of the pellets during an adsorption-desorption cycle showed a hysteresis in the range of sensitivity (Figure 7). This hysteresis is due to conservation or output delay of water molecules during desorption which is due to the porosity that hinders desorption of the water molecules.

The response time test performed for ML2 pellets sintered at different temperatures showed that the pellets

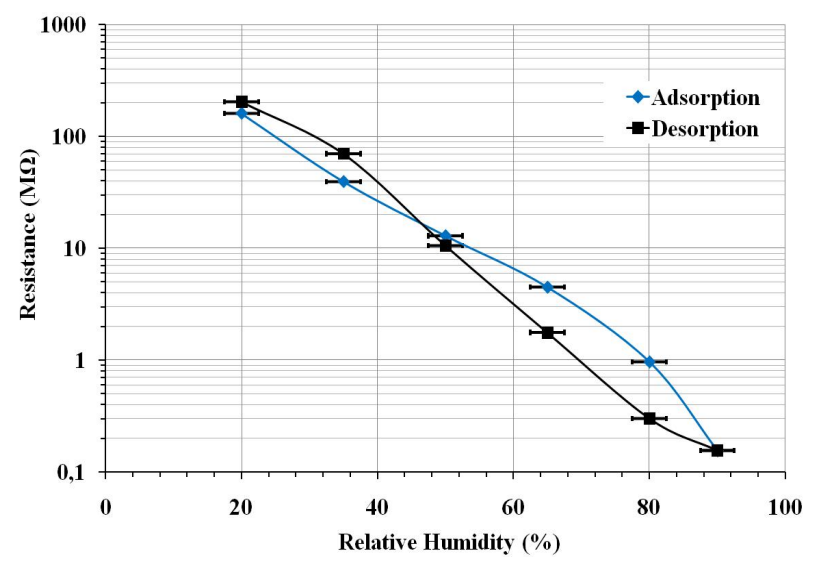

Figure 7. Resistance variation hysteresis of ML2 pellet sintered at $900^{\circ} \mathrm{C}$ as a function of the relative humidity percentage at $70 \mathrm{~V} \cdot \mathrm{mm}^{-1} \mathrm{DC}$. sintered at $1000^{\circ} \mathrm{C}$ have the better rapid and reproducible response time, with an adsorption time of 150 seconds and desorption very fast, 20 seconds. The capacity ranges from $7600 \mathrm{pF}$ at $95 \% \pm 2.5 \% \mathrm{RH}$ to $400 \mathrm{pF}$ at $4 \% \pm 2.5 \%$ $\mathrm{RH}$. On the contrary, desorption still remains incomplete (Figure 8). However, the response time of the ML2 pellet sintered at $900^{\circ} \mathrm{C}$ is slow 1000 seconds in adsorption and the desorption never reaches the initial value. We recall that the porosity in the sintered pellet at $1000^{\circ} \mathrm{C}(10 \% \pm$ $2 \%)$ is lower than that sintered at $900^{\circ} \mathrm{C}(18 \% \pm 2 \%)$, and small pores $(<0.1 \mu \mathrm{m})$ have a percentage of $2 \% \pm 2 \%$ in the first and $14 \% \pm 2 \%$ in the sintered pellet to $900^{\circ} \mathrm{C}$.

The best response time shown by the pellet ML2 sintered at $1000^{\circ} \mathrm{C}$, is accompanied by a high sensitivity of the measurement of surface resistance between $20 \%$ and $80 \% \mathrm{RH}$ in the range tested temperatures of the environment ranging from $20^{\circ} \mathrm{C}$ to $60^{\circ} \mathrm{C}$.

In the hot-cold oven (described before), controlled by continuous measuring of the temperature and the relative humidity, the relative humidity is stabilized by pulverizetion of water vapor molecule automatically and our measurements were established when the humidity was stable. The curve at $20^{\circ} \mathrm{C}$ (Figure 9) shows that the pellet has a resistance which decreases when the $\mathrm{RH}$ increases from $55 \mathrm{M} \Omega$ at $20 \% \mathrm{RH}$ up to $20 \mathrm{k} \Omega$ at $80 \% \mathrm{RH}$. However, the measured resistance is lower when the atmosphere is warmer. Note that the resistance values are similar for both temperatures $40^{\circ} \mathrm{C}$ and $60^{\circ} \mathrm{C}$.

The selectivity of the sensor is a very important property to quantify the actual RH in the air without being distorted by the presence of other gas molecules in the atmosphere of the measurement. Samples ML2 sintered at $1000^{\circ} \mathrm{C}$ showed a signal of $7000 \mathrm{pF}$ in an atmosphere saturated with water vapor (Figure 8) were tested in different gas atmospheres at $25^{\circ} \mathrm{C}$ by using the same device developed in the laboratory for the measurement of sample response time under ac field.

As described before, this device has two rooms, each with a humidity and temperature sensors. However the

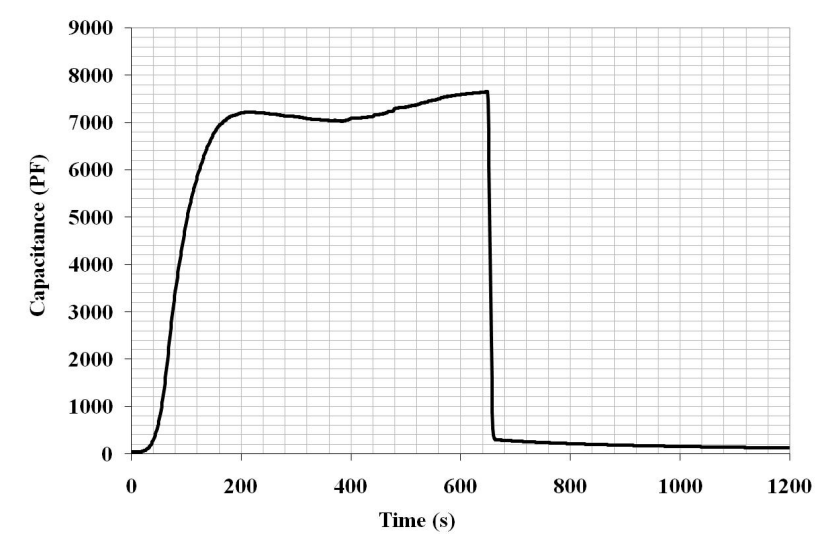

Figure 8. Response time of ML2 pellet sintered at $1000^{\circ} \mathrm{C}$ and characterized under $100 \mathrm{~Hz}$. 


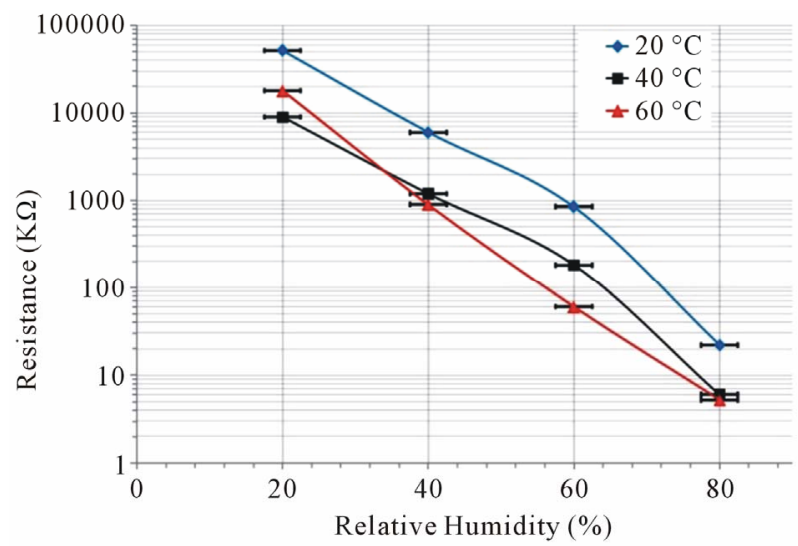

Figure 9. Resistive performance of ML2 pellets sintered at $1000^{\circ} \mathrm{C}$ on environments at $20^{\circ} \mathrm{C}, 40^{\circ} \mathrm{C}$ and $60^{\circ} \mathrm{C}$, depending on the relative humidity percentage.

first room was saturated, each time, by one of the three different molecules (methanol vapor, ethanol vapor and cigarette smoke), and in the second room a dry atmosphere (about $4 \% \pm 2.5 \% \mathrm{RH}$ ) is prepared. A cap equipped with a sample holder (where the ML2 samples are fixed) with wire connection to the bridge RLC controlled using a computer permits to measure the continuous capacitance values of the sample. Rotating cap allows the sample to pass from one room to another while measuring directly the change in capacitance as a function of time. When the ML2 sample was exposed to this three vapor-saturated atmosphere, the capacities measured did not exceed $5 \mathrm{pF}$ after 10 min of exposure (Figure 10).

This shows that the material is not sensitive to methanol to ethanol and cigarette smoke. It presents a selective sensitivity to the water molecule and the presence of impurities in the atmosphere to control does not distort the measurement. These results were compared to those obtained with a commercial sensor-based polymer (SHT75, Sensirion ${ }^{\circledR}$ ), used in our laboratory. The latter indicated RH equal to $100 \%, 62 \%$ and $91.5 \%$ successively in atmospheres saturated with molecules of methanol, ethanol and cigarette smoke. The resistive measurement of the samples is not possible until this moment by our device however it well be very important to measure it in these different saturated atmospheres.

\section{Conclusion}

Sintered pellet of $\mathrm{MgTiO}_{3}$ mixed with $2 \% \mathrm{LiF}(\mathrm{w} / \mathrm{w}$ ) showed higher sensitivity compared to the other compositions in a wide range of $\mathrm{RH}(20 \%-90 \% \mathrm{RH})$ and a reliable response time (150 seconds) for a percentage change in $\mathrm{RH}$ from $5 \%$ to $95 \%$. The best sintering temperature is verified $1000^{\circ} \mathrm{C}$. This compound gave a short and repeatable response time. It is important to note that this sensitivity is observed in the case of surface resistance measurements, while measurements of surface ca-

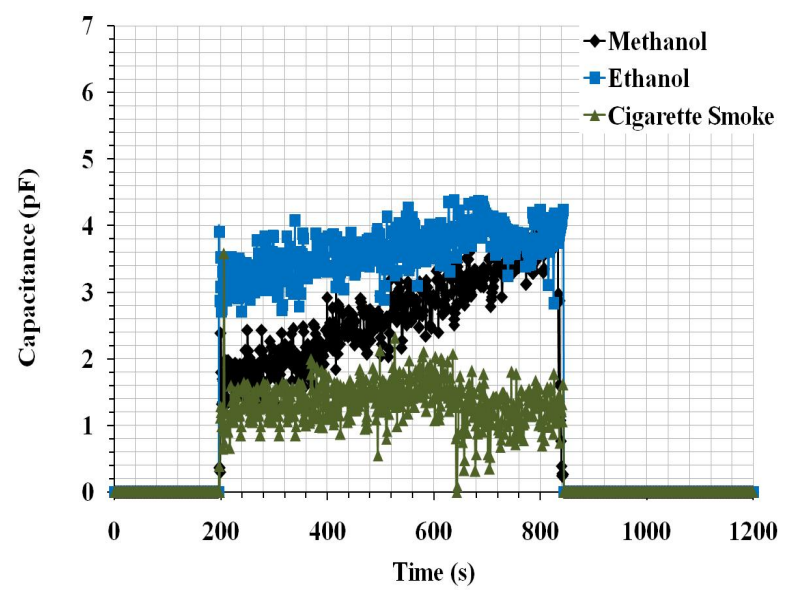

Figure 10. Selectivity test of ML2 pellet sintered at $1000^{\circ} \mathrm{C}$.

pacitance do not show an exploitable behavior for measurement of humidity above $60 \% \mathrm{RH}$. In the ambient atmosphere between $10 \%$ and $90 \% \mathrm{RH}$ the ML2 compound is sensitive and could be used as a ceramic humidity sensor. However the hysteresis problem remains unresolved and probably come from the porosity of our samples. This material shows as promising humidity sensitive part in the range $20 \%-90 \%$ RH with selectivity properties to water molecules. The capacitance measurement in the response time test shows that this material does not need a heat-cleaning step to releases the adsorbed water molecules.

\section{REFERENCES}

[1] E. Traversa, "Ceramic Sensors for Humidity Detection: The State-of-the-Art and Future Developments," Sensors and Actuators B: Chemical, Vol. B23, No. 2, 1995, pp. 135-156.

[2] T. Nitta, Z. Terada and S. Hayakawa, "Humidity-Sensitive Electrical Conduction of $\mathrm{MgCr}_{2} \mathrm{O}_{4}-\mathrm{TiO}_{2}$ Porous Ceramics," Journal of the American Ceramic Society, Vol. 63, No. 5-6, 1980, pp. 295-300.

[3] S. Pokhrel, B. Jeyaraj and K. S. Nagaraja, "HumiditySensing Properties of $\mathrm{ZnCr}_{2} \mathrm{O}_{4}-\mathrm{ZnO}$ Composites," Materials Letters, Vol. 57, No. 22-23, 2003, pp. 3543-3548. doi:10.1016/S0167-577X(03)00122-8

[4] Y. Shimizu, H. Okada and H. Arai, "Humidity-Sensitive Characteristics of Porous La-Ti-V-O Glass-Ceramics," Journal of the American Ceramic Society, Vol. 72, No. 3, 1989, pp. 436-441.

[5] T. J. Hwang and G. M. Choi, "Humidity Response Characteristics of Barium Titanate," Journal of the American Ceramic Society, Vol. 76, No. 3, 1993, pp. 766-768. doi:10.1111/j.1151-2916.1993.tb03675.x

[6] J. H. Anderson Jr. and G. A. Parks, "The Electrical Conductivity of Silica Gel in the Presence of Adsorbed Water," Journal of Physical Chemistry, Vol. 72, No. 10, 1968, pp. 3662-3668. doi:10.1021/j100856a051

[7] Q.-L. Zhang, H. Yang and J.-X. Tong, "Low-Temperature 
Firing and Microwave Dielectric Properties of $\mathrm{MgTiO}_{3}$ Ceramics with $\mathrm{Bi}_{2} \mathrm{O}_{3}-\mathrm{V}_{2} \mathrm{O}_{5}$," Materials Letters, Vol. 60, No. 9-10, 2006, pp. 1188-1191. doi:10.1016/i.matlet.2005.10.105

[8] J. Bernard, F. Belnou, D. Houivet and J.-M. Haussonne, "Low Sintering Temperature of $\mathrm{MgTiO}_{3}$ for Type I Capacitors," Journal of the European Ceramic Society, Vol. 25, No. 12 , 2005, pp. 2779-2783. doi:10.1016/i.jeurceramsoc.2005.03.139

[9] X. M. Chen, L. Li and X. Q. Liu, "Layered Complex Structures of $\mathrm{MgTiO}_{3}$ and $\mathrm{CaTiO}_{3}$ Dielectric Ceramics," Materials Science and Engineering: B, Vol. 99, No. 1-3, 2003, pp. 255-258. doi:10.1016/S0921-5107(02)00493-2

[10] J. Bernard, D. Houivet, M. Hervieu and J.-M. Haussonne, "Evidence of the Formation of a New Rock-Salt Type Compound $\mathrm{Li}_{2} \mathrm{MgTiO}_{4}$ and of Its Role on the Properties of the Li Doped $\mathrm{MgTiO}_{3}$," Solid State Sciences, Vol. 8, No. 6, 2006, pp. 598-605. doi:10.1016/j.solidstatesciences.2006.01.010

[11] C. Vigreux, B. Deneuve, J. El Fallah and J.-M. Haussonne,
"Effect of Acceptor and Donor Additives on the Properties of $\mathrm{MgTiO}_{3}$ Ceramics Sintered under Reducing Atmosphere," Journal of the European Ceramic Society, Vol. 21, No. 10-11, 2001, pp. 1681-1684. doi:10.1016/S0955-2219(01)00092-9

[12] J.-M. Haussonne, C. Carry, P. Bowen and J. Barton, "Céramiques et Verres Principes et Techniques D'élaboration: Vol. 16," Traité des Matériaux, Presse Polytechniques et Universitaires Romandes, Lausanne, 2005.

[13] J. Bernard, D. Houivet, M. Hervieu and J.-M. Haussonne, "Evidence of the Formation of a New Rock-Salt Type Compound $\mathrm{Li}_{2} \mathrm{MgTiO}_{4}$ and Its Role on the Properties of the Li Doped $\mathrm{MgTiO}_{3}$," Solid State Sciences, Vol. 8, No. 6, 2006, pp. 598-605. doi:10.1016/j.solidstatesciences.2006.01.010

[14] A. Kassas, J. Bernard, C. Lelievre, D. Houivet and T. Hamieh, "Sintering Study of Ceramic Material Based on Magnesium Titanate in Presence of Lithium Fluoride Additives," Journal of Materials Science and Engineering $(A \& B)$, Vol. 2, No. 7, 2012, pp. 550-559. 